\title{
Survival processing of faces
}

\author{
Adam C. Savine • Michael K. Scullin • \\ Henry L. Roediger III
}

Published online: 9 June 2011

(C) Psychonomic Society, Inc. 2011

\begin{abstract}
The mnemonic benefit of rating words according to their relevance in a survival scenario is well documented (e.g., Nairne, Thompson, \& Pandeirada, 2007). The present study examined whether the survival processing effect would extend to face stimuli. We tested this hypothesis in five experiments, using multiple survival and control scenarios, real and computer-generated face sets, withinand between-subjects designs, and several memory tests, as well as free recall of survival-relevant and survival-neutral attribute statements written about the person. Although the standard survival processing effect was obtained for survival-relevant and neutral attribute statements, the survival processing effect was not obtained for face memory across all experiments. These results identify an important boundary condition for survival processing benefits.
\end{abstract}

Keywords Survival processing · Face processing ·

Recognition $\cdot$ Recall $\cdot$ Memory

Nairne et al. (2007) suggested that human memory systems have evolved to retain information relevant to the fitness of the individual. Thus, processing information within the context of a survival-relevant scenario might provide memory benefits for information beyond that of normal encoding processes. This type of encoding is termed survival processing. In the standard survival processing paradigm, participants are instructed to imagine that they are in the grasslands of a foreign land without basic

\footnotetext{
A. C. Savine $(\bowtie) \cdot$ M. K. Scullin $\cdot$ H. L. Roediger III

Department of Psychology, Washington University,

St. Louis, MO 63130-4899, USA

e-mail: acsavine@go.wustl.edu
}

survival materials and to rate a list of words based on how relevant their referents would be to promoting success in the survival scenario. After a brief delay, participants are asked to recall or recognize the previously presented words, and performance in the survival condition is compared to performance in a control condition (e.g., pleasantness ratings of words). The typical finding is that survival processing leads to better retention, and (as discussed below) this outcome has been obtained relative to a wide variety of comparison tasks (Nairne \& Pandeirada 2008a, b). The present investigation sought to extend this work through examining survival processing of human faces.

The survival processing effect has been replicated with multiple sets of words in multiple laboratories (e.g., Kang, McDermott, \& Cohen, 2008; Nairne et al., 2007; Weinstein, Bugg, \& Roediger, 2008). The effect is robust across recognition and recall memory tests (Kang et al., 2008; Nairne et al., 2007) and occurs regardless of whether the rating condition (i.e., survival vs. control) is manipulated within or between subjects (Nairne et al., 2007; Nairne \& Pandeirada, 2010). Notably, the mnemonic benefit of survival processing has been demonstrated relative to a wide range of control conditions. In a single study, Nairne, Pandeirada, and Thompson (2008) demonstrated that survival processing produces better retention than imagery, pleasantness rating, self-reference, generation, and intentional learning-processing conditions that are considered to be some of the best for later retention. Furthermore, survival processing also benefits memory relative to processing words within the context of a bank robbery scenario (Kang et al.), a moving scenario (Nairne et al., 2007; Weinstein et al., 2008), a vacation scenario (Nairne et al., 2008), a scavenger/hunting contest scenario (Nairne, Pandeirada, Gregory, \& Van Arsdall, 2009), and even a scenario involving modern survival in a city (Nairne \& 
Pandeirada, 2010; Weinstein et al., 2008). Clearly, ancestrally relevant survival processing has mnemonic benefits.

To our knowledge, all published studies have used word stimuli or pictures of objects to demonstrate survival processing benefits. Most studies have used randomly selected, unrelated word lists (e.g., Nairne et al., 2009; Nairne et al., 2007; Weinstein et al., 2008). Other studies have demonstrated the survival processing effect for words in a categorized list (Nairne \& Pandeirada, 2008a; Otgaar \& Smeets, 2010; but see Butler, Kang, \& Roediger, 2009, for discrepant findings). The benefits of survival processing do not appear to be limited to verbal materials; at least one study (Otgaar, Smeets, \& van Bergen, 2010) has demonstrated survival processing benefits for pictures of objects that were selected to resemble the words used by Nairne et al. (2007). A natural next step is to examine whether the survival processing effect transfers to other nonverbal stimuli, and particularly to one class of stimuli that can be critical to survival- human faces.

We based our decision to examine survival processing of faces on three observations. First, survival processing has been likened to a levels-of-processing effect (Craik \& Lockhart, 1972; Craik \& Tulving, 1975), and such effects are not only observed with word stimuli, but also with face stimuli (Strnad \& Mueller, 1977; Winograd, 1976). Second, one of the original predictions of survival processing was that if "an item is processed in terms of its survival relevance, [it is expected] to be remembered well" (Nairne et al., 2007, p. 264). Thus, the survival processing advantage is expected to be relevant to a range of materials, not just to verbal learning. Third, if survival processing effects reflect an evolved preference for retaining information processed for its fitness value, then a survival processing advantage should be expected for faces. This seems to be a reasonable assumption because face recognition is a skill demonstrated by several nonhuman primates (including Old World monkeys; Dufour, Pascalis, \& Petit, 2006) and other mammals, such as sheep (Kendrick, da Costa, Leigh, Hinton, $\&$ Peirce, 2001). Moreover, as the ability to remember other humans appears to have great functional importance (e.g., for mating or detecting in- and out-members of a group), a plausible prediction is that processing people (faces) according to their utility in a survival scenario would result in better later recognition of those individuals relative to control scenarios.

The alternative hypothesis is that survival processing will not have an effect on face recognition. Successful face recognition requires one to make specific, configural discriminations (e.g., distance between nose and eyes; for a review, see Maurer, Grand, \& Mondloch, 2002), but survival processing might not augment such processes. Instead of boosting detail-level processing, survival processing might increase gist-level (reconstructive gestalt processes) processing. Otgaar and Smeets (2010) had participants rate semantically related words according to either survival or control scenarios, and later examined free recall of studied words versus nonstudied lure items. Consistent with the hypothesis that survival processing promotes gist-level processing, the survival processing condition demonstrated both greater veridical recall of words and greater false memories (i.e., recall of nonstudied lure items), relative to the control conditions. Thus, survival processing may bolster gist-level processing of stimuli, and if so, then survival processing might not benefit face recognition (which requires detail-level discriminations).

\section{Experiment 1}

We first attempted to replicate the survival processing advantage with faces by following Kang et al.'s (2008) design. To match the survival processing and control groups on arousal, novelty, and prior media exposure, Kang et al. compared the effects of survival processing to processing words according to their relevance in a bank robbery scenario. We adopted this bank robbery control group as well as other features of Kang et al.'s (Exp. 2) methodology, including their within-subjects (rating scenario) design, scenario-processing rating scale (1 to 5), number of stimuli (32 in each rating phase), number of participants $(N=48)$, retention interval (10 min of Tetris), and memory test (old/ new recognition test). The major difference between the Kang et al. study and the present study was that, instead of using word stimuli, we used face stimuli. Based on an evolutionary account of survival processing benefits (e.g., Nairne et al., 2007), we predicted that processing the faces according to a survival scenario would lead to better recognition of those faces relative to the bank robbery scenario.

\section{Method}

Participants and design A total of 48 Washington University undergraduates (35 female) participated for partial class credit. Rating scenario (survival vs. bank robbery) was manipulated within subjects.

Materials The faces (all male) were taken from the Yarkoni (Personal Communication, May 27, 2008) face database (Fig. 1, top). The 128 male faces (computer generated, without hair) were pseudorandomly selected such that the experimenter excluded faces that appeared highly unusual (due to being computer designed). By selecting the computer-generated faces, we intended to minimize the influence of nonfacial features (e.g., background, clothing, hair type). The selected faces were randomly assigned to 
Sample Face Stimulus: Experiment 1

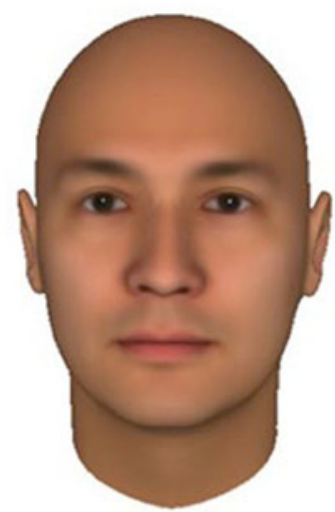

Sample Face Stimulus: Experiments 2-4

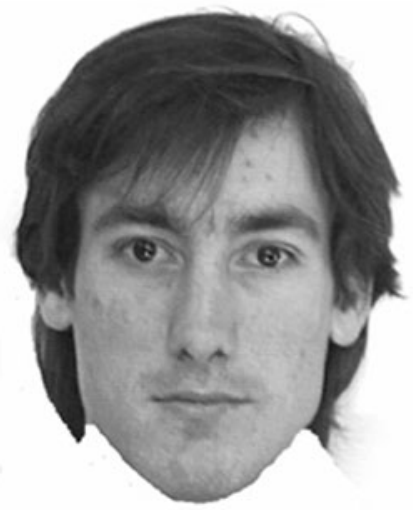

Fig. 1 Example face stimuli from Experiment 1 (computer generated; Yarkoni, personal communication) and Experiments 2-4 (http://pics. psych.stir.ac.uk/)

two lists (64 faces each), one for study and the other to serve as test lures. Each list was further divided so that equal numbers of faces (32) would be rated in the survival and bank robbery scenarios.

Procedure Participants were first instructed that they were going to see faces on the computer screen and rate these people from 1 (very unhelpful) to 5 (very helpful) according to their helpfulness in particular scenarios. The survival scenario instructions were modified from those in Kang et al.'s (2008) study to be applicable to faces. The instructions were as follows: "In this task we would like you to imagine that you are stranded in the grasslands of a foreign land, without any basic survival materials. Over the next few months, you'll need to find steady supplies of food and water and protect yourself from predators. We would like for you to imagine that there is another individual in the grasslands with you. We are going to show you a set of faces of whom the person may be. We would like you to rate how helpful this person would be in aiding your survival in this situation. Some of the people may be helpful and others may not—it's up to you to decide."
For the bank robbery scenario, participants read the following instructions: "In this task we would like you to imagine that you are leading a robbery of a well guarded bank. Over the next few months, you'll need to make a plan and gather any supplies you might need. We would like for you to imagine that there is another individual robbing the bank with you. We are going to show you a set of faces of whom the person may be. We would like you to rate how helpful this person would be in accomplishing your goals in this robbery situation. Some of the people may be helpful and others may not - it's up to you to decide."

After receiving the instructions to one scenario (e.g., survival), participants rated a block of 32 faces according to those instructions. On each rating trial, participants saw a fixation cross for $500 \mathrm{~ms}$, rated the face from 1 to 5 (within a 5 -s response window), and then saw a blank screen for $500 \mathrm{~ms}$. Participants then received the instructions to the other scenario (e.g., bank robbery) and rated a separate set of 32 faces according to that scenario's rating instructions. Scenario order (survival/bank robbery or bank robbery/survival) was counterbalanced; in addition, sets of faces were counterbalanced across survival, moving, and lure conditions.

After two blocks of rating faces (one block for survival, one block for the bank robbery), participants played Tetris for $10 \mathrm{~min}$ as a distractor task. Then, participants were told that they were going to be shown a set of faces and to decide whether or not they had seen the faces earlier by pressing the keys marked old and new (1 and 2, respectively, on the number pad). Each recognition task trial consisted of a fixation cross $(300 \mathrm{~ms})$, followed by a face that was old or new, and then a blank screen $(300 \mathrm{~ms})$. Recognition decisions to faces were self-paced, and 64 of the 128 faces were old.

\section{Results}

The probability of a Type I error was set to .05 .

Recognition test Proportions of hits and false alarms during the recognition test are listed in Table 1 . There was no rating scenario (survival or bank robbery control) effect for hits $(t<1)$, and false alarms were identical across groups because Rating Scenario was a within-subjects factor. Because the proportions of hits were somewhat low $(M=$ .56), we conducted a median split based on total performance (i.e., combined total correct hits and correct rejections) to examine whether a survival processing benefit would be observed in the high-level performers. However, within these high performers, there was still no recognition hits difference between the rating scenarios $\left(M_{\mathrm{Con}}=.64\right.$, $\left.M_{\text {Surv }}=.62 ; t<1\right)$. Furthermore, we obtained the same results for hits when examining female $(t<1)$ and male $(t<1)$ participants separately. 
Table 1 Proportions of hits and false alarms during the recognition test, across conditions and experiments, as well as mean rating and response time (RT) data during the rating phase
Standard deviations are in parentheses.

\begin{tabular}{|c|c|c|c|c|}
\hline & Hits & False Alarms & Mean Rating & Mean RT \\
\hline \multicolumn{5}{|l|}{ Experiment 1} \\
\hline Survival scenario & $\begin{array}{l}.56 \\
(.14)\end{array}$ & $\begin{array}{l}.43 \\
(.17)\end{array}$ & $\begin{array}{l}2.88 \\
(0.46)\end{array}$ & $\begin{array}{l}2,336 \\
(965)\end{array}$ \\
\hline Bank scenario & $\begin{array}{l}.58 \\
(.13)\end{array}$ & $\begin{array}{l}.43 \\
(.17)\end{array}$ & $\begin{array}{l}2.86 \\
(0.42)\end{array}$ & $\begin{array}{l}2,486 \\
(1,168)\end{array}$ \\
\hline \multicolumn{5}{|l|}{ Experiment 2} \\
\hline Survival hunting & $\begin{array}{l}.65 \\
(.15)\end{array}$ & $\begin{array}{l}.33 \\
(.11)\end{array}$ & $\begin{array}{l}2.93 \\
(0.44)\end{array}$ & $\begin{array}{l}2,280 \\
(980)\end{array}$ \\
\hline Contest hunting & $\begin{array}{l}.66 \\
(.15)\end{array}$ & $\begin{array}{l}.33 \\
(.11)\end{array}$ & $\begin{array}{l}2.91 \\
(0.43)\end{array}$ & $\begin{array}{l}2,245 \\
(1,044)\end{array}$ \\
\hline \multicolumn{5}{|l|}{ Experiment 3} \\
\hline Survival scenario & $\begin{array}{l}.66 \\
(.13)\end{array}$ & $\begin{array}{l}.27 \\
(.09)\end{array}$ & $\begin{array}{l}2.76 \\
(0.49)\end{array}$ & $\begin{array}{l}2,657 \\
(1,226)\end{array}$ \\
\hline Moving scenario & $\begin{array}{l}.69 \\
(.18)\end{array}$ & $\begin{array}{l}.24 \\
(.12)\end{array}$ & $\begin{array}{l}2.69 \\
(0.55)\end{array}$ & $\begin{array}{l}2,641 \\
(1,124)\end{array}$ \\
\hline \multicolumn{5}{|l|}{ Experiment 4} \\
\hline Survival help & $\begin{array}{l}.71 \\
(.12)\end{array}$ & $\begin{array}{l}.29 \\
(.18)\end{array}$ & $\begin{array}{l}2.81 \\
(0.41)\end{array}$ & $\begin{array}{l}2,188 \\
(856)\end{array}$ \\
\hline Survival threat & $\begin{array}{l}.67 \\
(.16)\end{array}$ & $\begin{array}{l}.27 \\
(.13)\end{array}$ & $\begin{array}{l}2.88 \\
(0.33)\end{array}$ & $\begin{array}{l}(2,279) \\
(956)\end{array}$ \\
\hline \multicolumn{5}{|l|}{ Experiment 5} \\
\hline Survival scenario & $\begin{array}{l}.79 \\
(.14)\end{array}$ & $\begin{array}{l}.11 \\
(.10)\end{array}$ & $\begin{array}{l}2.74 \\
(0.40)\end{array}$ & $\begin{array}{l}3,517 \\
(2,562)\end{array}$ \\
\hline Moving scenario & $\begin{array}{l}.78 \\
(.14)\end{array}$ & $\begin{array}{l}.10 \\
(.09)\end{array}$ & $\begin{array}{l}2.64 \\
(0.37)\end{array}$ & $\begin{array}{l}2,894 \\
(1,632)\end{array}$ \\
\hline
\end{tabular}

Rating phase To remain consistent with the survival processing literature, we examined mean ratings and response times during the scenario rating phase. These results are presented in Table 1 . Mean ratings $(t<1)$ and mean response times $[t(47)=1.03]$ did not differ between the survival and bank robbery scenario conditions. Scenario rating values during the rating phase were also not associated with recognition hits [survival, $r(47)=.08, \mathrm{n}$. s.; control, $r(47)=.12$, n.s.] or mean response times [survival, $r(47)=-.04$, n.s.; control, $r(47)=.06$, n.s.]. Moreover, recognition hits were not associated with mean response times during the rating phase [survival, $r(47)=$ .07 , n.s.; control, $r(47)=.11$, n.s.].

\section{Discussion}

The results of Experiment 1 suggested that survival processing might not benefit later recognition of faces. This finding was contrary to our initial hypothesis (based upon an evolutionary account of survival processing effects; e.g., Nairne et al., 2007) and was inconsistent with the reliable finding that survival processing benefits memory for words. However, the null finding might be explained by Otgaar and Smeets's (2010) account of survival processing effects, in that survival processing may lead to gist-level face processing, whereas effective face recognition requires detail-level configural processing (Maurer et al., 2002).

To avoid prematurely concluding that survival processing effects do not occur with face stimuli, we conducted another experiment to address some possible limitations of Experiment 1. First, recognition performance was somewhat low in Experiment 1 [though note that the hit rate was significantly above the false alarm rate, $t(47)=6.3$, which might have been partially due to the length of the retention interval and the specific materials used (computer-generated faces)]. We addressed this issue in Experiment 2 by shortening the retention interval and using pictures of real faces. In addition, we utilized different survival and control scenario instructions to generalize our findings.

\section{Experiment 2}

Nairne et al. (2009) demonstrated the importance of fitnessrelevant processing by comparing memory for words rated in two hunting scenarios, one of which encouraged fitnessrelevant processing (e.g., hunting to feed one's tribe). The 
control scenario had a similar structure (e.g., a modern-day hunting contest) but did not encourage fitness-relevant processing. Consistent with the hypothesis that fitnessrelevant processing leads to better retention, performance was better in the scenario that involved hunting to feed one's tribe than in the scenario that involved hunting to win a contest. In the present experiment, we adapted these scenarios to be relevant to face processing. Furthermore, we used real faces and doubled the number of participants (relative to Exp. 1) to boost our power to detect a survival processing effect, if present.

Experiment 2 included another twist to overcome another possible limitation of Experiment 1. One possible reason a survival processing effect would not have been observed in the previous experiment is that such processing may have an ancillary effect on memory for faces that is not being measured by a standard recognition test. For example, survival processing may make the context in which the face was observed more memorable, without affecting face recognition per se. Additionally, in prior work, Bell and Buchner (2010a, 2010b) demonstrated enhanced source memory for faces processed with other sorts of fitness-relevant context information. For these reasons, in Experiment 2 we included a source memory test after the recognition test to determine whether participants would recognize the correct scenario in which the face occurred with a greater probability in the survival condition than in the hunting contest condition. If survival processing increases one's ability to recall the context in which the face was previously processed, we should observe a positive effect of survival processing in the source-monitoring test in Experiment 2.

\section{Method}

Participants and design A total of 97 Washington University undergraduates (58 females) participated for partial class credit. These participants had not participated in Experiment 1. Rating scenario (survival hunting vs. contest hunting) was manipulated within subjects.

Materials A set of 128 pictures of real (i.e., not computergenerated) male human faces were taken from the Psychological Image Collection at Stirling (http://pics.psych.stir.ac. uk/; see Fig. 1, bottom). The backgrounds of each picture were whitened out using Adobe Photoshop 5.0 so as to avoid recognition via contextual details. The selected faces were randomly assigned to two lists (64 faces each). Each list was further divided so that equal numbers of faces (32) would be rated in the survival and bank robbery scenarios. The remaining faces served as lures during the recognition task. Lures and targets were counterbalanced across list sets and scenario subsets.
Procedure The procedure was similar to that of Experiment 1, with the following exceptions. First, the rating scenarios were adapted from Nairne et al.'s (2009, Exp. 2) procedure. The survival hunting scenario instructions were as follows: "In this task, please imagine that you are living long ago in the GRASSLANDS OF A FOREIGN LAND. You are in charge of picking a small group that will be in charge of contributing meat to feed your tribe. You and your group will need to hunt big game, trap small animals, or even fish in a nearby lake or river. Hunters often have to travel great distances, pursue animals through unfamiliar terrain, and successfully return home. Whatever the conditions, you and your group must hunt successfully to feed your tribe. We are going to show you a set of faces, and we would like you to rate how helpful each of these people would be in your attempt to hunt successfully for food. Some of the people may be helpful and others may not-it's up to you to decide."

The contest hunting scenario instructions were as follows: "In this task, please imagine that you have been invited to participate in a HUNTING CONTEST. You are in charge of picking a small group that will be in charge of contributing captured game to the team effort. You and your group will need to hunt big game, trap small animals, or even fish in a nearby lake or river. Members of the team often have to travel great distances, pursue animals through unfamiliar terrain, and successfully return to the contest center. Whatever the conditions, you and your group must hunt successfully to help your team win the contest. We are going to show you a set of faces, and we would like you to rate how helpful each of these people would be in your attempt to hunt successfully. Some of the people may be helpful and others may not-it's up to you to decide."

After rating faces according to each scenario (order counterbalanced), participants played Tetris as a distractor activity for $5 \mathrm{~min}$ (rather than $10 \mathrm{~min}$, as in Exp. 1). The recognition test was analogous to that used in Experiment 1, with one small change. Instead of responding that a face was old or new by pressing keys labeled old and new, participants were told to determine whether a face was presented earlier or not by pressing keys marked $Y$ (yes) and $N$ (no) (1 and 2, respectively, on the number pad).

Following the recognition test, participants were told that they were going to be shown each face from the rating phase again. They were instructed to determine whether they had seen the face in the scenario in which they were rating people on surviving in the grasslands of a foreign land (hunting to feed the tribe) or in the scenario in which they were rating faces for a hunting game to win a team contest. They were told to press 1 for survival (tribe) and 2 for contest (team) (the response keys were counterbalanced across participants). Each source memory trial included a fixation cross $(300 \mathrm{~ms})$, a face presented earlier (i.e., during 
the rating phase), and a blank screen (300 ms). Source memory decisions were self-paced, and the order of face presentation was randomized.

\section{Results}

Recognition test Our primary interest was in recognition memory performance, and the results are presented in Table 1. False alarms were identical across scenario rating conditions because scenario rating was manipulated within-subjects. Consistent with Experiment 1, there was no difference between the survival hunting and contest hunting conditions $(t<1)$, and this finding was consistent for female $(t<1)$ and male $(t<1)$ participants. High performers on the recognition test (determined by median splits of combined hits and correct rejections) did not show a survival hunting advantage $\left(M_{\text {Con }}=.68, M_{\text {Surv }}=\right.$ $.69 ; t<1)$.

Rating phase As in Experiment 1, neither mean ratings nor mean response times during the rating phase differed between the survival hunting and contest hunting conditions ( $t \mathrm{~s}<1$; see Table 1). Scenario rating values during the rating phase were also not associated with later recognition [survival, $r(96)=.06$, n.s.; control, $r(96)=-.03$, n.s.] or mean response time [survival, $r(96)=-.08$, n.s.; control, $r(96)=.14$, n.s.]. Recognition hits were also not associated with mean response times during the rating phase [survival, $r(96)=-.02$, n.s.; control, $r(96)=.08$, n.s.].

Source memory test The source memory test was difficult for participants, though performance was significantly better than chance [i.e., greater proportions of hits than of false alarms: $t(190)=1.97, p<.05]$. Survival hunting source memory performance $(M=51.5 \%)$ was quite similar to contest hunting performance $(M=50.8 \%)$. Moreover, high performers (determined by median splits of combined hits and correct rejections) did not show better source memory for survival hunting scenario faces $(M=52.0 \%)$ than for contest hunting scenario faces $(M=52.3 \% ; t<1)$.

\section{Discussion}

Consistent with Experiment 1, no survival processing effect occurred for faces. Although using pictures of real people and shortening the retention interval improved overall recognition (relative to Exp. 1), no benefit of survival processing was observed. Furthermore, there was no evidence for an advantage of survival processing on the source memory test for faces, either.

In Experiment 3, we examined different conditions to determine whether a survival processing effect would occur with faces under other plausible conditions in which this effect has been obtained with word lists. Specifically, we compared a survival processing scenario to a moving (to a new home) scenario, and we conducted this manipulation between subjects (in contrast to the within-subjects tests used in Exps. 1 and 2). Moreover, we included a few additional tests that would not be confounded by task difficulty to further test the hypothesis that survival processing may have an effect on later face perception.

\section{Experiment 3}

In Experiment 3, we used a moving scenario as our control condition because we considered it to differ more clearly from our survival scenario (relative to the previous two control scenarios). To avoid any possible interference effects related to using a within-subjects procedure, we elected to manipulate survival and moving scenarios between subjects, because other researchers (e.g., Nairne et al., 2007; Otgaar, Smeets, \& van Bergen, 2010) have found positive effects of survival processing in between-subjects designs.

We further pursued the different ways in which survival processing might have an effect on face memory or face processing by examining the following: (1) confidence ratings of recognition decisions, (2) influences of survival processing on the future perception of presented faces, and (3) how likely individuals would be to help each person (face) presented. We predicted that if survival processing does not increase binary (yes/no) recognition of faces (as in Exps. 1-2), it may influence the graded recognition strength of the faces (as measured by a 6-point confidence scale). After the recognition test, the faces were presented again, and participants rated them on dimensions of attraction, fear, anger, and trustworthiness. We predicted that, consistent with evolutionary theory, the survival processing group (relative to the control group) might rate faces higher on dimensions that embody evolutionarily beneficial traits (e.g., attractiveness, trustworthiness; but see Haselton \& Buss, 2000, for a different perspective). Individuals then rated how willing they would be to help the individual (face) presented. Here, we predicted that individuals in the survival processing group would report that they were more willing to help the individual (assuming that social networking can increase an individual's fitness).

Method

Participants and design A total of 48 Washington University undergraduates who had not participated in the previous survival processing experiments received partial class credit for participating. Participants were randomly assigned to the survival $(n=26)$ and moving $(n=22)$ scenario conditions. 
Materials The materials were identical to those of Experiment 2, except that only one list of 64 faces (32 studied and 32 unstudied) was used because rating scenario was a between-subjects manipulation.

Procedure Participants in the survival scenario condition received the same instructions used in the survival condition in Experiment 1. Participants in the moving condition received the following instructions, which were adapted from Nairne et al.'s (2007) study: "In this task we would like you to imagine that you are planning to move to a new home in a foreign land. Over the next few months, you'll need to locate and purchase a new home and transport your belongings. We would like for you to imagine that there is another individual moving with you. We are going to show you a set of faces of whom the person may be. We would like you to rate how helpful this person would be in aiding you in your move. Some of the people may be helpful and others may not-it's up to you to decide."

After the rating phase, participants performed a distractor activity (Tetris) for $10 \mathrm{~min}$ (the retention interval was lengthened because fewer faces were studied during the rating phase). The following recognition test was identical to that used in Experiment 2, except that after each recognition decision, participants rated how confident they were in their recognition judgment, from 1 (not at all) to 6 (extremely). On each recognition trial, participants saw a fixation cross for $300 \mathrm{~ms}$, made a recognition decision to the presented face, saw a blank screen for $200 \mathrm{~ms}$, made a confidence judgment, and then saw another blank screen for $200 \mathrm{~ms}$. The process then repeated.

Next, participants were instructed that they would be asked to rate the same (32) faces, as well as (32) new faces, on several dimensions. In separate blocks, participants rated how afraid, angry, attractive, and trustworthy each of the 64 faces was on a scale from 1 to 7 . Block order and face presentation within each block were randomized. In a fifth block, participants were asked to answer (from 1 to 7) how willing they would be to help the person (e.g., with a favor, if he was in trouble, etc.).

\section{Results}

Recognition test The results of the recognition test were consistent with the data from the previous experiments. As shown in Table 1, survival processing did not affect hits or false alarms relative to the moving condition (both $t \mathrm{~s}<1$ ). Likewise, when subtracting false alarms from hits, recognition did not differ between the survival condition $(M=$ $.39)$ and the control condition $(M=.45)[t(46)=1.42$, n.s.]. There was no effect of scenario condition on recognition memory performance when examining data from only males $(t<1)$ or only females $(t<1)$. Whether individuals were high or low recognition memory performers (determined by median splits of combined hits and correct rejections) did not change performance patterns across conditions $(t \mathrm{~s}<1)$.

Rating phase Consistent with the previous experiments' results, the survival condition and the moving condition did not differ in rating response times or mean ratings during the rating phase (both $t \mathrm{~s}<1$; see Table 1). Furthermore, scenario rating values during the rating phase were not associated with later recognition [survival, $r(25)=.09$, n.s.; moving, $r(21)=.11$, n.s.] or mean response times [survival, $r(25)=.02$, n.s.; control, $r(21)=.04$, n.s.]. Again, recognition hits were not associated with mean response times during the rating phase [survival, $r(25)=.10$, n.s.; control, $r(21)=.16$, n.s.].

Confidence and face characteristic tests We next examined the relationship between confidence, recognition judgment, and scenario condition. Higher confidence ratings $\left(M_{\text {Surv }}=\right.$ 4.69) accompanied recognition hits relative to confidence ratings of recognition misses $\left(M_{\text {Surv }}=3.41\right)$ in the survival condition $[t(25)=9.03, p<.001]$ as well as in the moving condition $[M \mathrm{~s}=4.57$ and 3.43 for hits and misses, respectively; $t(21)=7.13, p<.001]$. However, there was no effect of scenario condition on confidence judgments to recognition hits or misses (both $t \mathrm{~s}<1$ ).

We also examined mean fear, anger, attraction, and trust ratings across conditions by conducting a $2 \times 2 \times 2 \times 4$ mixed ANOVA that included Scenario Condition (survival or moving) and Gender (male or female) as betweensubjects factors, as well as Dimension (anger, fear, attraction, trust) and Face (new or old) as within-subjects factors. The dimension main effect was significant, $F(3$, $138)=8.73, M S E=.44$ (Greenhouse-Geisser), but no other main effect or interaction was significant $\left(F_{\mathrm{s}}<1\right)$. Therefore, though the faces varied intrinsically on the measured dimensions, initially processing the faces according to survival relevance $\left(M_{\text {Fear }}=2.68, M_{\text {Attrac }}=2.79\right.$, $\left.M_{\text {Anger }}=3.11, M_{\text {Trust }}=3.25\right)$ did not affect face perception relative to the moving condition $\left(M_{\mathrm{Fear}}=2.52, M_{\mathrm{Attrac}}=\right.$ $2.80, M_{\text {Anger }}=3.07, M_{\text {Trust }}=3.05$ ).

We also tested whether survival processing affected the likelihood that an individual would be willing to help a person (that they had previously rated). There was no significant difference in mean ratings between the survival condition $(M=3.79)$ and the moving condition $(M=3.64)$ $(t<1)$.

\section{Discussion}

Survival processing did not improve face recognition or increase the confidence of recognition judgments. Further, 
it did not affect the manner in which faces were later perceived (according to a variety of fitness-relevant dimensions). The failure to find such effects of survival processing on perceived face characteristics or memory dovetails with recent work demonstrating that survival processing effects are not observed during implicit memory tests (Tse \& Altarriba, 2010), although the present tests were not sensitive to the effects of prior processing.

\section{Experiment 4}

In the prior experiments, participants had rated faces according to how helpful they would be in helping one survive in a foreign environment. However, survival relevance can also be indexed by evaluating one's environment in relation to the potential threats that may be present. In fact, if participants process stimuli (particularly faces) in accordance with threatening or negative cover stories (such as cheating or general meanness), then memory for those faces is sometimes enhanced (Becker, et al., 2010; Bell \& Buchner, 2010a, 2010b; Kinzler \& Shutts, 2008). Thus, it is possible that if faces were rated in terms of being potential threats to one's survival, the survival processing effect might indeed be obtained for face memory. We tested this hypothesis in Experiment 4, with a between-subjects manipulation (survival help vs. survival threat) that was otherwise structured identically to that of Experiment 3.

\section{Method}

Participants and design A total of 51 Washington University undergraduates who had not participated in the previous survival processing experiments received their choice of partial class credit or $\$ 5$ for participating. Participants were randomly assigned to the survival help $(n=26)$ and survival threat scenario conditions $(n=25)$. Two individuals ( 1 from each condition) completed only the rating phase of the data, and thus are excluded from the analyses.

Materials The materials were identical to those of Experiment 3.

Procedure Participants in the survival help condition received the following instructions: "In this task we would like you to imagine that you are stranded in the grasslands of a foreign land, without any basic survival materials. Over the next few months, you'll need to find steady supplies of food and water and protect yourself from predators. We would like for you to imagine that there is another individual in the grasslands with you. Individuals in this land are sometimes helpful, and you will need to determine whether or not this person is a potential help to your survival. We are going to show you a set of faces of whom the person may be. We would like you to rate how helpful this person would be in aiding your survival in this situation. Some of the people may be helpful and others may not-it's up to you to decide."

Participants in the survival threat condition received the following instructions: "In this task we would like you to imagine that you are stranded in the grasslands of a foreign land, without any basic survival materials. Over the next few months, you'll need to find steady supplies of food and water and protect yourself from predators. We would like for you to imagine that there is another individual in the grasslands with you. Individuals in this land are sometimes hostile, and you will need to determine whether or not this person is a potential threat to your survival. We are going to show you a set of faces of whom the person may be. We would like you to rate how threatening each person might be in this situation. Some of the people may be threats to your survival and others may not-it's up to you to decide."

After the rating phase, the procedure was identical to that of Experiment 3.

\section{Results}

Recognition test There were no significant differences in face recognition memory (hits or false alarms) in the survival threat group relative to the survival help group (Table 1 ; both $t \mathrm{~s}<1$ ). Also, no significant differences in recognition were present between conditions when subtracting false alarms from hits (survival threat, $M=.40$; survival help, $M=.42 ; t<1$ ). There was no effect of scenario condition on recognition memory performance (hits and false alarms) when examining data from only males $(t \mathrm{~s}<1)$ or only females $(t \mathrm{~s}<1)$, and whether individuals were high or low recognition-memory performers (determined by median split of combined hits and correct rejections) did not change performance patterns across conditions $(t \mathrm{~s}<1)$. As a post-hoc analysis, we also tested both the survival threat and survival help scenarios against the independently collected moving control scenario from Experiment 3 (which was collected using the exact same procedure with a comparable sample size). Neither of the survival scenarios demonstrated significant differences in face recognition memory (hits or false alarms) relative to the control group (Table 1; all $t \mathrm{~s}<1$ ).

Rating phase Consistent with the previous experiments' results, the survival help and survival threat conditions did not differ in rating response times or mean ratings during the rating phase (both $t \mathrm{~s}<1$; see Table 1). Furthermore, scenario rating values during the rating phase were not associated with later recognition [survival threat, $r(24)=$ 
-.173 , n.s.; survival help, $r(25)=.116$, n.s.] or mean response times [survival threat, $r(24)=-.123$, n.s.; survival help, $r(25)=.109$, n.s.]. Again, recognition hits were not associated with mean response times during the rating phase [survival threat, $r(24)=.202$, n.s.; survival help, $r$ $(25)=-.189$, n.s.].

Confidence and face characteristic tests We next examined the relationship between confidence, recognition judgment, and scenario condition. Higher confidence ratings $(M=$ 4.85) accompanied recognition hits relative to confidence ratings of recognition misses $(M=4.27)$ in the survival threat condition, $t(24)=4.60, p<.001$; the same pattern was also significant in the survival help condition $(M \mathrm{~s}=$ 4.54 and 3.91 for hits and misses, respectively), $t(25)=$ $4.12, p<.001$. Moreover, face recognition confidence was nominally (but not significantly) higher in the survival threat condition than in the survival help condition, $t(49)=$ $1.88, p=.066$.

Mean fear, anger, attraction, and trustworthiness ratings were examined across conditions by conducting a $2 \times 2 \times 2$ $\mathrm{x} 4$ mixed ANOVA that included Scenario Condition (survival threat or survival help) and Gender (male or female) as between-subjects factors, as well as Dimension (anger, fear, attraction, trust) and Face (new or old) as within-subjects factors. The dimension by scenario condition interaction effect was significant, $F(3,46)=5.26$, $M S E=.38$ (Greenhouse-Geisser) (all other $F_{S}<1$ ). This interaction was driven by the finding that processing faces in terms of a survival threat scenario, relative to the survival help scenario, led to higher anger ratings $\left(M_{\text {Threat }}=3.73\right.$, $\left.M_{\text {Help }}=2.87 ; \mathrm{t}(49)=2.17, p<.05\right)$ and lower attractiveness ratings $\left(M_{\text {Threat }}=2.76, M_{\text {Help }}=3.40 ; \mathrm{t}(49)=2.02, p<.05\right)$, but had little or no effect on trustworthiness ratings $\left(M_{\text {Threat }}=3.18, M_{\text {Help }}=3.23 ; t<1\right)$ and fear ratings $\left(M_{\text {Threat }}=2.86, M_{\text {Help }}=2.69 ; t<1\right)$.

We also tested whether survival processing affected the likelihood that an individual would be willing to help a person (that they had previously rated). As might be expected, mean ratings illustrated that participants were more willing to help a person they had previously processed in accordance with a help scenario $(M=3.84)$ relative to a threat scenario $(M=2.78), t(49)=2.34$, $p<.05$.

\section{Discussion}

Survival threat processing did not improve face recognition relative to a survival help condition (cf. Exps. 1-3) or Experiment 3's control (moving) group. Although encoding faces within a survival threat context altered how the faces were later perceived on anger and attractiveness dimensions, relative to the survival help condition, the survival threat scenario did not benefit face recognition. These data are inconsistent with the idea that the survival processing effect may obtain for face memory if the faces are initially processed as potential threats rather than potential helpers.

\section{Experiment 5}

One possible account for the discrepancy between the robustness of survival processing effects on words (Nairne \& Pandeirada, 2008b) and the lack of a survival processing effect for faces (Exps. 1-4) is that words represent objects with discrete, known functions, whereas the usefulness of a particular person may be less clear when initially processing a face. For example, when presented with the word knife, one knows its purpose can be for hunting and cutting, and one can envision the circumstances in which a knife would be helpful for survival. In contrast, the assessment of another human in a survival condition may be difficult without knowing more about the person.

Thus, in the present experiment, we tested whether presenting faces along with statements that were derived from categories identified by Nairne and Pandeirada (2008b) as evolutionarily relevant (survival, social, kin, navigation, and reproduction) would result in a survival processing benefit. For comparison, we also included statements that were not evolutionarily relevant (i.e., neutral statements). If survival processing effects were not obtained in Experiments 1-4 simply because participants lacked any information about the people they were rating, then a survival processing effect should be obtained in the present experiment, because evolutionarily relevant (and neutral) information was associated with each face. In contrast, if survival processing has its effects via biasing individuals toward gist-based processing (Otgaar \& Smeets, 2010), then the addition of statements to the face rating procedure might have no benefit to face recognition (because face recognition requires detailed configural discriminations; Maurer et al., 2002).

\section{Method}

Participants and design A total of 51 Washington University undergraduates who had not participated in the previous survival processing experiments received partial class credit for participating. Participants were randomly assigned to the survival $(n=26)$ and moving $(n=25)$ scenario conditions.

Materials The face materials were identical to those used in Experiments $2-4$, except that we used only 32 faces (16 studied and 16 unstudied) because of the added load of encoding statements. 
The list of the statements is presented in the Appendix. There were six categories of statements, which were (1) survival relevant, (2) kin relevant, (3) reproduction relevant, (4) navigation relevant, (5) socially relevant, or (6) neutral (e.g., "his office is a pleasant shade of blue"). The first five categories (i.e., all but neutral) were adopted from Nairne and Pandeirada (2008b, see their Table 1). Sixteen statements were generated per category, with half of the statements framed positively (e.g., "he easily assembles tents") and the other half framed negatively (e.g., "he failed to assemble tents").

Procedure The survival and moving scenario instructions were the same as those used in Experiment 3. In the rating phase, a face was presented in the top half of the screen, and six different statements were presented (cumulatively), with each statement remaining on the screen for $5 \mathrm{~s}$ before the next statement was added. One statement from each of the categories was presented along with each face, with three of the statements negatively valenced and three of the statements positively valenced. The statements and faces were pseudorandomly presented to ensure that each face was presented with the same statements for each participant. This was done to better equate task experience across individuals. After reading all (six) statements for a face, the participant rated (from 1 to 5) the face according to the relevant survival (or moving) scenario.

Following the rating phase, participants performed a distractor activity (Tetris) for $5 \mathrm{~min}$ (the retention interval was shortened because more total items- 16 faces and 96 statements - were studied). The following face recognition test was identical to that used in Experiments 1-4. Afterward, participants were given a piece of paper and instructed to free recall as many of the presented statements as possible in a 5 -min time period. Free recall of the statements was scored by two independent raters, who scored responses based on the number of idea units accurately recalled for each participant (not verbatim text). The idea unit scores from each rater correlated very highly $(r=.93, p<.001)$. Thus, the free-recall analyses were based on the averaged scores of both raters.

\section{Results}

Recognition test As is shown in Table 1, survival processing did not affect face recognition hits $(t<1)$ or false alarms $(t<1)$ relative to the moving condition. Moreover, when subtracting false alarms from hits, recognition test performance still did not differ between the survival and control conditions (both $M \mathrm{~s}=.68 ; t<1$ ). Furthermore, the recognition memory results were again consistent when only examining male $(t<1)$ or female $(t<1)$ participants. The results still did not vary when individuals were split into high versus low performers (defined by median splits of combined hits and correct rejections) on the recognition memory test $(t \mathrm{~s}<1)$.

Free recall of statements Whereas we did not obtain a survival processing effect for face stimuli, we detected some evidence for survival processing effects when examining recall of the statements. The data are in Figure 2, where it appears that survival processing benefited survival and neutral statements. Using a 2 (Scenario) $x 2$ (Gender) $\mathrm{x}$ 6 (Statement Type) mixed ANOVA, we found a significant scenario by statement type interaction $[F(5,46)=4.81$, $M S E=.83$ (Greenhouse-Geisser)]. The interaction was due to a survival processing benefit for survival-relevant statements $\left[M_{\text {Surv }}=7.42, M_{\text {Moving }}=5.40 ; t(50)=2.38, p<.05\right]$ and neutral statements $\left[M_{\text {Surv }}=3.31, M_{\text {Moving }}=2.08\right.$; $\mathrm{t}(50)=2.33, p<.05]$, but with no effect for the navigation, reproduction, or social statements (all $t \mathrm{~s}<1$ ). Interestingly, we found that for kin statements, free recall was better in the moving condition relative to the survival condition $\left[M_{\text {Surv }}=2.23, M_{\text {Moving }}=3.80 ; t(50)=3.08, p<.01\right]$. The main effect of survival processing was insignificant $[F(2,48)=1.84$, n.s. $]$, but there was a main effect of statement type $[F(5,46)=9.16, p<.001]$ that was driven primarily by higher recall for survival-relevant statements (see the Appx. for the mean proportion recall for each statement).

When breaking down the individual statements in the experiment by valence, we found that positively valenced statements were recalled more often overall than the negatively valenced statements $\left(M_{\mathrm{Pos}}=.25, M_{\mathrm{Neg}}=.21\right)$, $t(47)=3.15, p<.005$. Valence, however, did not interact with the factors of Scenario, Statement Type, or Gender (largest $F=1.37$ ). However, because the statements were not normed on Arousal, Perceived Valence, Distinctiveness, and other factors that might affect the memorability of individual items, we suggest caution in interpreting the main effect of valence and the main effect of statement type.

Rating phase Consistent with the previous experiments' results, the survival condition and the moving condition did not differ in mean rating response times $[t(49)=1.03$, n.s.] nor mean ratings during the rating phase $(t<1$; see Table 1). In addition, scenario rating values during the rating phase were not associated with later recognition [survival, $r(25)=.14$, n.s.; moving, $r(24)=.08$, n.s.], mean response times [survival, $r(25)=.07$, n.s.; moving, $r(24)=-.03$, n.s.], or mean free recall [survival, $r(25)=$ .23 , n.s.; moving, $r(24)=.14$, n.s.]. Moreover, recognition hits were not associated with mean response times during the rating phase [survival, $r(25)=.04$, n.s.; moving, $r(24)=-.07$, n.s.]. 
Fig. 2 Number of statements recalled across statement types (survival, kin, navigation, reproduction, social, and neutral) as a function of survival and control (i.e., moving) conditions. Error bars represent standard errors of the means. ${ }^{*} p<$ $.05 .{ }^{* *} p<.01$

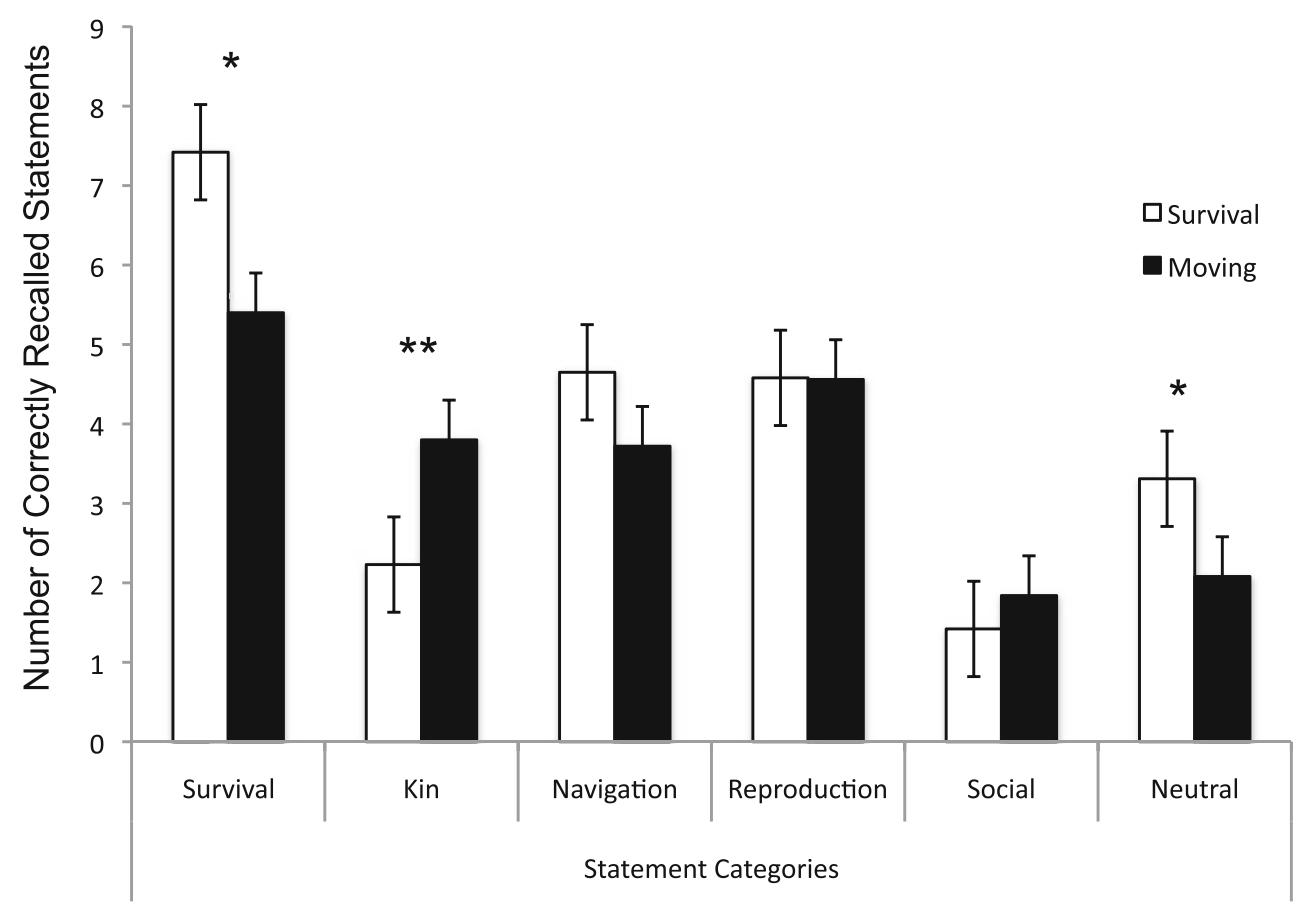

\section{Discussion}

The critical finding of the present experiment was that whereas no survival processing effect was obtained for face recognition (consistent with Exps. 1-4), we did obtain some evidence for survival processing benefits for the free recall of both survival-relevant and neutral statements. Some of these benefits may be attributable to congruency processing; for example, survival scenarios may lead to preferential processing and encoding of survival statements (Butler et al., 2009). Likewise, in the moving condition, which should prime consideration of family in undergraduate participants (e.g., moving with family, away from family to college, etc.), free recall of kin statements exceeded that in the survival condition. Importantly, because survival processing benefits were also demonstrated for the neutral statements, congruency cannot account for all of the observed survival processing effects.

\section{General discussion}

In the present research, we tested whether survival processing would produce better recognition of studied faces than a matched control condition. Though robust memory benefits have been observed for word stimuli (e.g., Kang et al., 2008; Nairne et al., 2007; Weinstein et al., 2008), pictures of objects (Otgaar et al., 2010), and now for neutral statements (Exp. 5), this effect did not extend to face recognition.

In the sequence of five experiments, we investigated what we considered to be the most likely candidates for a failure to produce the survival processing effect in faces. The absence of a survival processing effect for faces could not be explained by the use of a within- or between-subjects design, idiosyncratic effects of face sets (both computergenerated and real faces were used), a particular survival scenario description (two different fitness-relevant, ancestral survival scenarios were used), orienting survival processing toward helpfulness or threat posed by others, or the scenario employed for the control comparison (bank robbery, contest hunting, and moving scenarios were all used). Moreover, by observing no face memory benefits in the survival help as well as the survival threat conditions in Experiment 4, as well as when we provided concrete "functions" to the faces in Experiment 5, we have provided strong evidence that the lack of benefits for face memory cannot be explained by an insufficient engagement of survival processing. Furthermore, the lack of a survival processing effect on the recognition memory of faces cannot be explained by insufficient statistical power: Recognition memory performance was slightly (but not significantly) better in the control conditions than in the survival conditions in Experiments 1-3.

The survival processing effect is robust for word stimuli, and it is therefore curious that the effect does not obtain with face stimuli. In the following paragraphs, we evaluate the validity of nonevolutionary (congruity, levels of processing, gist processing) and evolutionary hypotheses for accounting for the words/faces discrepancy, so as to promote better understanding of the proximate mechanism(s) of the typical survival processing effect. 
Butler et al. (2009) suggested that the survival processing effect might be explained as a congruity effect, which is the experimental finding of greater recall of items rated highly on a relevant dimension as compared to items rated lower on that dimension. The idea is that in a survival processing experiment, one or two words may be rated as more relevant to a survival scenario relative to a control scenario (though the mean ratings remain similar), thereby producing better retention in the survival condition. Butler et al.'s explanation of the survival processing effect seems reasonable, based on their experimental results, but the congruity effect may not explain all existing findings. Nairne and Pandeirada (2011) reported a series of survival processing effects that could not be explained by congruity. Furthermore, in Experiment 5, we also found a survival processing effect for neutral statements that could not be explained purely by principles of congruity.

Another nonevolutionary explanation of survival processing effects is that survival processing is simply a levelsof-processing effect. However, deeper processing of faces is known to benefit face memory, relative to shallower processing (Strnad \& Mueller, 1977; Winograd, 1976). Therefore, our finding of no survival processing benefit to face memory suggests that the proximate mechanism of the typical survival processing effect (for words) may not be akin to a levels-of-processing effect.

Another potential explanation for the discrepancy between survival benefits to words but not to faces is that survival scenarios promote gist-level processing (Otgaar \& Smeets, 2010). Otgaar and Smeets had participants rate semantically related words according to a survival scenario or a control scenario (e.g., moving). They reported that survival processing boosted veridical recall of words but also led to increases in false memories. Based on this evidence, Otgaar and Smeets proposed that "survival processing causes participants to rely more heavily on gist processing" (p. 1014). According to this account, face recognition might not benefit from survival processing because details (i.e., particular face configurations; Maurer et al., 2002) rather than semantic gist are necessary to correctly recognize a face. Thus, our results were consistent with a gist-based account of the proximate mechanism of typical survival processing effects.

A fourth possible explanation for the discrepant outcome between words and faces, which capitalizes on evolutionary theory, is that memory for faces may not have been a specific ancestral need, at least relative to objects or the functions of objects (represented by word stimuli). For example, in the cheater detection literature, research has demonstrated no enhanced recognition memory for faces of cheaters, even though cheater detection is assumed to be an old and evolutionarily relevant skill (Buchner, Bell, Mehl, \& Musch, 2009; Mehl \& Buchner, 2008). One reason that face stimuli do not show sensitivity to evolutionarily relevant manipulations could be that humans evolved in small bands, which might not have interacted regularly with members of opposing bands. If different bands did not interact regularly, then there might have been minimal need for a memory system to encode and store the physical features of strangers. In contrast, there would still be great evolutionary pressures on memory for hunting grounds, food stores, and the uses of objects. Thus, it is possible that memory for the configural features of faces may prove insensitive to any manipulation of survival processing. Of course, this hypothesis is clearly speculative and ex post facto; had survival processing benefited retention of faces, the outcome could have been endorsed as supporting an evolutionary account.

Our experiments were not specifically designed to legislate between the existing proximate-mechanism hypotheses of the typical survival processing effect (for words). However, our data do offer some suggestions. The lack of a survival processing effect for faces was generally inconsistent with congruity and levels-ofprocessing explanations, but consistent with a gist-level processing account. More recent accounts that survival processing may lead to benefits when either item-based or relational processing is necessary, but not both in the same paradigm (Burns, Burns, \& Hwang, 2011), or that survival processing is otherwise "special" (Nairne \& Pandeirada, 2008a, p. 377) are less clearly informed by the present experiments.

In conclusion, the present research provides evidence that the mnemonic benefit of survival processing does not occur with faces as to-be-remembered items. There may exist some specific set of circumstances under which survival processing benefits face recognition, but such conditions do not seem to follow simply from prior survival processing research on words. It is important to remember that the standard survival processing hypothesis suggests that, if individuals are all given the same stimuli, then ". . . survival advantages cannot be attributed to the inherent qualities of the to-be-remembered items. . . . it is the nature of the processing that produces the enhancement" (Nairne, 2010, p. 6). Our data do not support this strong hypothesis in one important domain, because even though memory systems may be "tuned to remember information that is processed in terms of its fitness value" (Nairne et al., 2009, p. 740), this tuning may not encompass the information provided by human faces.

Author Note We thank Geoff Maddox, Megan Smith, and Yichi Guo for their help with portions of this project. We thank Tal Yarkoni for sharing his face stimulus set with us. We are also appreciative of John Seamon and Vaughn Becker for their helpful comments on an earlier version of the manuscript and for suggestions that led to Experiment 4. 


\section{Appendix}

Table 2 A listing of the statement items used in Experiment 5, and the proportions indicating how often the particular statements were recalled across subjects

\begin{tabular}{|c|c|c|c|c|c|}
\hline $\begin{array}{l}\text { Item } \\
\text { Number }\end{array}$ & Classification & Positive Frame & $\begin{array}{l}\text { Prop. } \\
\text { Recalled }\end{array}$ & Negative Frame & $\begin{array}{l}\text { Prop. } \\
\text { Recalled }\end{array}$ \\
\hline 1 & Survival & He can start fires with two sticks. & .47 & He can start fires only with matches. & .54 \\
\hline 2 & Survival & He easily assembles tents. & .42 & He failed to assemble a tent. & .39 \\
\hline 3 & Survival & He carries water bottles. & .37 & He does not carry water bottles. & .26 \\
\hline 4 & Survival & He can identify edible berries. & .37 & He cannot identify edible berries. & .30 \\
\hline 5 & Survival & He did reach Eagle Scout status. & .40 & He did not reach Eagle Scout status. & .35 \\
\hline 6 & Survival & He built a spear. & .32 & He failed to build a spear. & .35 \\
\hline 7 & Survival & He hunts elk successfully. & .37 & He hunts elk poorly. & .19 \\
\hline 8 & Survival & He scared away a bear. & .65 & He fled from a bear. & .58 \\
\hline 1 & Navigation & He knows how to use a compass. & .49 & $\begin{array}{l}\text { He does not know how to use a } \\
\text { compass. }\end{array}$ & .37 \\
\hline 2 & Navigation & He can use the stars to navigate. & .37 & He cannot use the stars to navigate. & .21 \\
\hline 3 & Navigation & He is very good at reading maps. & .33 & He cannot read a map. & .21 \\
\hline 4 & Navigation & He never gets lost. & .14 & He always gets lost. & .26 \\
\hline 5 & Navigation & $\begin{array}{l}\text { He is very good at tracking weather } \\
\text { patterns. }\end{array}$ & .25 & He cannot track weather patterns. & .16 \\
\hline 6 & Navigation & He always remembers landmarks. & .23 & He never remembers landmarks. & .14 \\
\hline 7 & Navigation & He can use his shadow to tell direction. & .32 & $\begin{array}{l}\text { He cannot use his shadow to tell } \\
\text { direction. }\end{array}$ & .18 \\
\hline 8 & Navigation & He can navigate using animal tracks. & .40 & He cannot navigate using animal tracks. & .14 \\
\hline 1 & Reproduction & He has sex with only one partner. & .46 & He has sex with many partners. & .47 \\
\hline 2 & Reproduction & He speaks confidently with women. & .18 & He speaks awkwardly with women. & .13 \\
\hline 3 & Reproduction & He is big and strong. & .42 & $\mathrm{He}$ is small and weak. & .33 \\
\hline 4 & Reproduction & $\begin{array}{l}\text { Genetic disease does not run in his } \\
\text { family. }\end{array}$ & .14 & Genetic diseases run in his family. & .23 \\
\hline 5 & Reproduction & Most women find him very attractive. & .49 & Most women do not find him attractive. & .30 \\
\hline 6 & Reproduction & He has many financial resources. & .23 & He has limited financial resources. & .13 \\
\hline 7 & Reproduction & He has physical stamina. & .12 & He lacks physical stamina. & .09 \\
\hline 8 & Reproduction & He smells good. & .33 & He smells bad. & .49 \\
\hline 1 & Social exchange & $\begin{array}{l}\text { He commonly donates to charitable } \\
\text { causes. }\end{array}$ & .04 & He rarely donates to charitable causes. & .05 \\
\hline 2 & Social exchange & He always reciprocates favors. & .18 & He never reciprocates favors. & .19 \\
\hline 3 & Social exchange & He always keeps promises to others. & .14 & He rarely keeps promises to others. & .11 \\
\hline 4 & Social exchange & $\begin{array}{l}\text { He never violates the personal space of } \\
\text { strangers. }\end{array}$ & .11 & $\begin{array}{l}\text { He often violates the personal space of } \\
\text { strangers. }\end{array}$ & .11 \\
\hline 5 & Social exchange & He respects his superiors at work. & .07 & He disregards his superiors at work. & .11 \\
\hline 6 & Social exchange & $\begin{array}{l}\text { He enjoys attending gatherings with } \\
\text { friends. }\end{array}$ & .04 & $\begin{array}{l}\text { He does not enjoy attending gatherings } \\
\text { with friends. }\end{array}$ & .05 \\
\hline 7 & Social exchange & $\begin{array}{l}\text { He works at his best in collaborative } \\
\text { groups. }\end{array}$ & .11 & $\begin{array}{l}\text { He works at his worst in collaborative } \\
\text { groups. }\end{array}$ & .09 \\
\hline 8 & Social exchange & $\begin{array}{l}\text { He rarely performs actions for his } \\
\text { personal gain. }\end{array}$ & .04 & $\begin{array}{l}\text { He often performs actions for his } \\
\text { personal gain. }\end{array}$ & .05 \\
\hline 1 & Kin & $\begin{array}{l}\text { He listens to the advice of his family in } \\
\text { tough times. }\end{array}$ & .12 & $\begin{array}{l}\text { He ignores the advice of his family in } \\
\text { tough times. }\end{array}$ & .12 \\
\hline 2 & Kin & $\begin{array}{l}\text { He would rather spend time with family } \\
\text { than other acquaintances. }\end{array}$ & .33 & $\begin{array}{l}\text { He would rather spend time with other } \\
\text { acquaintances than family. }\end{array}$ & .28 \\
\hline 3 & Kin & Most in his family are physically fit. & .09 & Few in his family are physically fit. & .09 \\
\hline 4 & Kin & $\begin{array}{l}\text { His family worked hard to give him a } \\
\text { chance to succeed in life. }\end{array}$ & .21 & $\begin{array}{l}\text { His family didn't work hard to give him } \\
\text { a chance to succeed in life. }\end{array}$ & .00 \\
\hline 5 & Kin & His family members enjoy his company. & .30 & $\begin{array}{l}\text { His family members do not enjoy his } \\
\text { company. }\end{array}$ & .19 \\
\hline
\end{tabular}


Table 2 (continued)

\begin{tabular}{|c|c|c|c|c|c|}
\hline $\begin{array}{l}\text { Item } \\
\text { Number }\end{array}$ & Classification & Positive Frame & $\begin{array}{l}\text { Prop. } \\
\text { Recalled }\end{array}$ & Negative Frame & $\begin{array}{l}\text { Prop. } \\
\text { Recalled }\end{array}$ \\
\hline 6 & Kin & He wants to have children. & .16 & He does not want to have children. & .18 \\
\hline 7 & Kin & $\begin{array}{l}\text { None in his family have cancer or heart } \\
\text { disease. }\end{array}$ & .09 & $\begin{array}{l}\text { Much of his family has cancer or heart } \\
\text { disease. }\end{array}$ & .14 \\
\hline 8 & Kin & $\mathrm{He}$ is a responsible father. & .33 & $\mathrm{He}$ is an irresponsible father. & .30 \\
\hline 1 & Neutral & His cursive writing is clean. & .00 & His cursive writing is messy. & .02 \\
\hline 2 & Neutral & He paints landscapes well. & .09 & He paints landscapes poorly. & .05 \\
\hline 3 & Neutral & $\begin{array}{l}\text { He always remembers to turn off his cell } \\
\text { phone for movies. }\end{array}$ & .12 & $\begin{array}{l}\text { He does not always remember to turn off } \\
\text { his cell phone for movies. }\end{array}$ & .12 \\
\hline 4 & Neutral & $\begin{array}{l}\text { His work office is a pleasant shade of } \\
\text { blue. }\end{array}$ & .26 & $\begin{array}{l}\text { His work office is an unpleasant shade } \\
\text { of blue. }\end{array}$ & .33 \\
\hline 5 & Neutral & He seldom plays music too loud. & .09 & He often plays music too loud. & .122 \\
\hline 6 & Neutral & His watch tells the time correctly. & .28 & His watch has stopped working. & .25 \\
\hline 7 & Neutral & His favorite class in college was small. & .30 & $\begin{array}{l}\text { His least favorite class in college was } \\
\text { small. }\end{array}$ & .18 \\
\hline 8 & Neutral & He clips his fingernails regularly. & .21 & $\begin{array}{l}\text { He does not clip his fingernails } \\
\text { regularly. }\end{array}$ & .18 \\
\hline
\end{tabular}

\section{References}

Becker, V. D., Anderson, U. S., Neuberg, S. L., Maner, J. K., Shapiro, J. R., Ackerman, J. M., et al. (2010). More memory bang for the attentional buck: Self-protection goals enhance encoding efficiency for potentially threatening males. Social Psychological and Personality Science, 1, 182-189.

Bell, R., \& Buchner, A. (2010a). Justice sensitivity and source memory for cheaters. Journal of Research in Personality, 44, 677-683. doi:10.1016/j.jrp.2010.08.011.

Bell, R., \& Buchner, A. (2010b). Valence modulates source memory for faces. Memory \& Cognition, 38, 29-41. doi:10.3758/ MC.38.1.29.

Buchner, A., Bell, R., Mehl, B., \& Musch, J. (2009). No enhanced recognition memory, but better source memory for faces of cheaters. Evolution and Human Behavior, 30, 212-224. doi:10.1016/j.evolhumbehav.2009.01.004.

Burns, D. J., Burns, S. A., \& Hwang, A. J. (2011). Adaptive memory: Determining the proximate mechanisms responsible for the memorial advantages of survival processing. Journal of Experimental Psychology. Learning, Memory, and Cognition, 37, 206218. doi:10.1037/a0021325.

Butler, A. C., Kang, S. H. K., \& Roediger, H. L., III. (2009). Congruity effects between materials and processing tasks in the survival processing paradigm. Journal of Experimental Psychology. Learning, Memory, and Cognition, 35, 1477-1486. doi:10.1037/a0017024.

Craik, F. I. M., \& Lockhart, R. S. (1972). Levels of processing: A framework for memory research. Journal of Verbal Learning and Verbal Behavior, 11, 671-684.

Craik, F. I. M., \& Tulving, E. (1975). Depth of processing and the retention of words in episodic memory. Journal of Experimental Psychology. General, 104, 268-294.

Dufour, V., Pascalis, O., \& Petit, O. (2006). Face processing limitation to own species in primates: A comparison study in brown capuchins, Tonkean macaques and humans. Behavioural Processes, 73, 107-113.

Haselton, M. G., \& Buss, D. M. (2000). Error management theory: A new perspective on biases in cross-sex mind reading. Journal of Personality and Social Psychology, 78, 81-91.
Kang, S. H. K., McDermott, K. B., \& Cohen, S. M. (2008). The mnemonic advantage of processing fitness-relevant information. Memory \& Cognition, 36, 1151-1156. doi:10.3758/MC.36. 6.1151 .

Kendrick, K. M., da Costa, A. O., Leigh, A. E., Hinton, M. R., \& Peirce, J. W. (2001). Sheep don't forget a face. Nature, 414, 165166.

Kinzler, K. D., \& Shutts, K. (2008). Memory for "mean" over "nice": The influence of threat on children's face memory. Cognition, 107, 775-783.

Maurer, D., Grand, R. L., \& Mondloch, C. J. (2002). The many faces of configural processing. Trends in Cognitive Sciences, 6, 255260.

Mehl, B., \& Buchner, A. (2008). No enhanced memory for faces of cheaters. Evolution and Human Behavior, 29, 35-41.

Nairne, J. S. (2010). Adaptive memory: Evolutionary constraints on remembering. In B. H. Ross (Ed.), The psychology of learning and motivation (Vol. 53, pp. 1-32). Burlington: Academic Press.

Nairne, J. S., \& Pandeirada, J. N. S. (2008a). Adaptive memory: Is survival processing special? Journal of Memory and Language, 59, 377-385. doi:10.1016/j.jml.2008.06.001.

Nairne, J. S., \& Pandeirada, J. N. S. (2008b). Adaptive memory: Remembering with a Stone-Age brain. Current Directions in Psychological Science, 17, 239-243. doi:10.1111/j.1467-8721. 2008.00582.x.

Nairne, J. S., \& Pandeirada, J. N. S. (2010). Adaptive memory: Ancestral priorities and the mnemonic value of survival processing. Cognitive Psychology, 61, 1-22. doi:10.1016/j.cogpsych. 2010.01.005.

Nairne, J. S., \& Pandeirada, J. N. S. (2011). Congruity effects in the survival processing paradigm. Journal of Experimental Psychology. Learning, Memory, and Cognition, 37, 539-549. doi:10.1037/a0021960.

Nairne, J. S., Pandeirada, J. N. S., Gregory, K. J., \& Van Arsdall, J. E. (2009). Adaptive memory: Fitness relevance and the huntergatherer mind. Psychological Science, 20, 740-746. doi:10.1111/ j.1467-9280.2009.02356.x.

Nairne, J. S., Pandeirada, J. N. S., \& Thompson, S. R. (2008). Adaptive memory: The comparative value of survival processing. Psychological Science, 19, 176-180. doi:10.1111/j.1467-9280.2008. 02064.x. 
Nairne, J. S., Thompson, S. R., \& Pandeirada, J. N. S. (2007). Adaptive memory: Survival processing enhances retention. Journal of Experimental Psychology. Learning, Memory, and Cognition, 33, 263-273. doi:10.1037/0278-7393.33.2.263.

Otgaar, H., \& Smeets, T. (2010). Adaptive memory: Survival processing increases both true and false memory in adults and children. Journal of Experimental Psychology. Learning, Memory, and Cognition, 36, 1010-1016. doi:10.1037/a0019402.

Otgaar, H., Smeets, T., \& van Bergen, S. (2010). Picturing survival memories: Enhanced memory after fitness-relevant processing occurs for verbal and visual stimuli. Memory \& Cognition, 38, 23-28. doi:10.3758/MC.38.1.23.
Strnad, B. N., \& Mueller, J. H. (1977). Levels of processing in facial recognition memory. Bulletin of the Psychonomic Society, 9, 17-18.

Tse, C.-S., \& Altarriba, J. (2010). Does survival processing enhance implicit memory? Memory \& Cognition, 38, 1110-1121. doi:10.3758/MC.38.8.1110.

Weinstein, Y., Bugg, J. M., \& Roediger, H. L., III. (2008). Can the survival recall advantage be explained by basic cognitive processes? Memory \& Cognition, 36, 913-919. doi:10.3758/ MC.36.5.913.

Winograd, E. (1976). Recognition memory for faces following nine different judgments. Bulletin of the Psychonomic Society, 8, 419421. 